\title{
Construction of Operation System of Maker Space in Colleges and Universities and Effective Supply Strategy
}

\author{
Yunqian Yi \\ Economic and Trade College, Shandong Management University, No.3500 Dingxiang Road, \\ Changqing University Town, Jinan, Shandong, China \\ yiyunqian@126.com
}

Keywords: Maker Space, innovation and entrepreneurship, effective supply.

\begin{abstract}
The maker space in colleges and universities is an important position for the cultivation of innovative and entrepreneurial talents, but many universities have entered into the misunderstanding of development, only focusing on space construction while ignoring the content construction, and paying too much attention on the performance of incubation while neglecting the cultivation of sprit and ability of innovation and entrepreneurship. It is the relative weakness in supply side that makes its numerous demands in teachers, students and society not be excavated, which is essentially difficult to serve the development of innovation and entrepreneurship. The current situation of innovation and entrepreneurship supported by maker space in colleges and universities was investigated in this paper, and then put forward the operation system of maker space in colleges and universities for the cultivation of innovative and entrepreneurial talents and the social service, and propose the implementation strategy about how to strengthen the effective supply of maker space.
\end{abstract}

\section{Research Background}

In the past two years, with the encouragement of the national policy, the construction of maker space has developed rapidly throughout the country, and the number of entrepreneurs and entrepreneurial service institutions has soared in a short period. As shown in Innovation and Entrepreneurship White Paper in 2016 issued by the Tencent research institute, only from 2014 to 2015, the number of domestic maker space has increased from more than 50 to more than 2,300, an increase of 46 times, while the data from Torch Center of Ministry of Science and Technology show that as of April 2017, the number of maker space in China has exceeded 4,200.

In this nationwide trend, college students are the main force of innovation and entrepreneurship, so colleges and universities have built the platform of innovation and entrepreneurship for students more actively. In December 2016 and August 2017, the Ministry of Education has identified 200 demonstrative colleges and universities of deepening innovation and entrepreneurship education reform in two batches, and the maker space has been continuously emerging in the above colleges and universities, which have become the important positions for the cultivation of innovative and entrepreneurial talents. However, there are some problems emerged in the construction and operation of innovation and entrepreneurship platform in colleges and universities, for example, the 
innovation and entrepreneurship education is not closely integrated with professional education, professional teachers' consciousness and ability of innovation and entrepreneurship are insufficient, there is no specialized agencies in schools to manage all resources to achieve coordinated development, only focus on space construction rather than content construction, and pay much attention to the performance of incubation rather than the cultivation of spirit and ability of innovation and entrepreneurship. It is the relative weakness in supply side that makes its numerous demands in teachers, students and society not be excavated, which is essentially difficult to serve the development of innovation and entrepreneurship.

\section{Concept, Feature and Functional Orientation of Maker Space in Colleges and Universities}

\subsection{Concept Interpretation}

Based on the interpretation of national files, such as Guiding Opinions of the State Council on the Development of Maker Space to Promote Public Innovation and Entrepreneurship, the maker space is a new convenient and open service platform for innovation and entrepreneurship with low cost and total factor, which is constructed through the market mechanism, professional services and capitalization approach by making full use of the Internet and the Open Source technology(General Office of the State Council, 2015). As the brand new organization form and service platform, it can provide working space, cyberspace, social space and resource sharing space for entrepreneurs, thus promoting knowledge sharing and realizing multidisciplinary integration(Zhanren Wang, Haibin Liu, Zhongyuan Li, 2016). Currently, many colleges and universities are exploring the new mode to construct the maker space, aiming at constructing a unique platform for innovation and entrepreneurship by using educational resources and alumni resources in universities on the basis of training system combining theory with practice, such as the Tsinghua x-lab, Peking University entrepreneurship incubation camp, BUPT WIN innovation and entrepreneurship practice base, Shandong University sigma maker space, etc.

\subsection{Stage of Development}

In fact, the colleges and universities construct the innovation and entrepreneurship platform for college students through the mode of school enterprise cooperation, which is not a new thing that happened in the last two years. The traditional incubator is equivalent to the 1.0 version of the maker space, which mainly provides venues and training guidance; in the aspect of oriented object, the 2.0 version of maker space is wider than traditional incubator, whose characteristic of opening reflects the requirement of "widespread entrepreneurship and innovation" with larger service scope, almost no barriers to entry, thus providing not only resource sharing and practice space, but also one-stop services including enterprise registration, policy consulting, investment and financing approach, business model construction, etc.; while the latest 3.0 version of maker space emphasizes supply-demand matching and social service, and at this time, the maker space not only provides the venue and comprehensive basic services, but also has the advantages of technical platform, which can open up the upstream and downstream resources of the industrial chain, and integrate its own resources to form a benign operation. 
Table 1 Comparison between Different Stages of Development of Maker Space.

\begin{tabular}{|c|c|c|}
\hline $\begin{array}{c}\text { Stages of } \\
\text { Development }\end{array}$ & $\begin{array}{c}\text { Profit } \\
\text { Point }\end{array}$ & $\begin{array}{c}\text { Features } \\
\text { and Contents }\end{array}$ \\
\hline Maker Space 1.0 & $\begin{array}{c}\text { Property fee and } \\
\text { site rent }\end{array}$ & $\begin{array}{c}\text { Provide practice venues and } \\
\text { training guidance. }\end{array}$ \\
\hline Maker Space 2.0 & $\begin{array}{c}\text { Rent and income } \\
\text { from basic } \\
\text { services }\end{array}$ & $\begin{array}{c}\text { Provide resource sharing, practice } \\
\text { space, enterprise training guidance } \\
\text { and one-stop comprehensive basic } \\
\text { services. }\end{array}$ \\
\hline Maker Space 3.0 & $\begin{array}{c}\text { Service income, } \\
\text { investment and } \\
\text { social service }\end{array}$ & $\begin{array}{c}\text { Provide venues and comprehensive } \\
\text { basic services, with technology } \\
\text { platform, profitability, and supply- } \\
\text { demand matching by self resources } \\
\text { integration. }\end{array}$ \\
\hline
\end{tabular}

\subsection{Characteristic Advantage}

Unlike the general maker space in the market, being based on the campus is the most important feature of the maker space in colleges and universities. At the same time, colleges and universities have mastered the two major resource advantages of hardware and software, which is served as the basic conditions for innovation, avoiding the lack of professional laboratories and technical service platform, insufficient maker and other limitations.

\subsubsection{Mutual Integration of Hardware and Software Resources}

The construction of the maker space has more and more emphasized professional operation, and the intensive cultivation needs to be supported by professional technical service platform, while those are the hardware resources including libraries and laboratories in universities, and the software resources including teaching force of interdisciplinary and team of scientific research experts that makes schools depend on the perfect infrastructure construction to provide incubation sites and entrepreneurial services with the superposition of universities' characteristics.

\subsubsection{High Degree of Talent Aggregation}

The pure digital growth of the maker space can not reflect the real market demand, and the entrepreneurial market has appeared the phenomenon of foaming. A lot of maker spaces in Beijing, Shanghai and other first-tier cities have been in deficit with low settled rate due to the service homogenization, and the situation of "insufficient maker" emerged in the maker space of Xiamen with the station utilization rate of only 51\%. However, in colleges and universities, students can enter into the maker space with "low threshold, zero cost, and no burden", as long as students are interested and willing, they can gather to participate in innovation and entrepreneurship activities at any time, which makes the maker space in colleges and universities be active for a long time with many batches of college student makers and team.

\subsection{Functional Orientation}

Colleges and universities with their own advantages and functions can realize the maximum value output to students, teachers and society only by fully excavating and integrating the function of innovation and entrepreneurship education of the maker space in colleges and universities. The 
maker space in colleges and universities should not consider the success rate of project transformation as the main measurement standard, but should focus on the students' skill training of innovation and entrepreneurship, the cultivation of students' spirit of innovation and entrepreneurship, and the influence of innovation and entrepreneurship culture in campus(Haomin Zhang, Lei Du, Jun Ma, 2011). The maker space in colleges and universities should have four functions:

\subsubsection{Practice Guidance Base}

As a "training and coaching" space, colleges and universities should make good use of resources such as universities, cooperative enterprises, alumni, successful maker, etc., set up the relatively stable special and part-time teaching staff, form a training system combining theory with practice, and reduce the entry threshold, thus create a learning platform for all the people who are interested in innovation and entrepreneurship to improve themselves.

\subsubsection{Maker Sharing Base}

The maker space in colleges and universities should provide the platform of communication, sharing and cooperation for entrepreneurs, focus on the cultivation of students' innovative spirit and the campus innovative culture, make use of entrepreneurial salon and other special activities to achieve the purposes of mutual enlightenment and mutual incentive, and also make use of the space to recruit partners and organize entrepreneurial teams for projects.

\subsubsection{Information Radiation Base}

Although the state has issued many policies to help college students to start their own businesses, but students have little social experience and limited ability of channel docking and resource utilization, while the maker space can sort the related policies into categories to be released on the platform of information sharing timely, and also can open up a site to set up the "green channel of policy " to assist the students to handle the procedures of administrative examination and approval, so that the national policies can be implemented on the ground.

\subsubsection{Resource Integration Base}

The maker space in colleges and universities with the mode of providing service platform and open resources can help the students without enough market experience to reduce the cost of trialand-error. The college students can not only make full use of hardware infrastructure provided by schools, but also obtain the matching software resources, including financing channels, training guidance, practice teaching, resource docking and other integrated services, so as to solve the problems of capital, goods supply and market in the process of starting an undertaking.

\section{Survey on Innovation and Entrepreneurship Promoted by Maker Space in Colleges and Universities}

\subsection{Outstanding Problems in the Construction of Maker Space in Colleges and Universities}

The construction of maker space in colleges and universities plays an indispensable role in the cultivation of students' innovative spirit and practical ability. However, according to the field visits and the investigation of many college students' entrepreneurship demonstration platforms, it was found that the development of maker space is not as satisfactory as expected. As the construction and operation of such innovation and entrepreneurship platform enter a relatively stable period, 
some problems gradually appear.

\subsubsection{High Failure Rate in Entrepreneurship}

Innovation needs time and entrepreneurship is difficult, so accumulation is very important for an excellent entrepreneur. As the economic and social development have grown to the size of today, some flow opportunities or opportunity entrepreneurship are getting less and less because of poor project feasibility, unreasonable profit model, projects without continuity and so on, thus causing the failure rate of college students' entrepreneurial projects is much higher than the success rate.

\subsubsection{Entrepreneurship Mentors with Uneven Qualities}

Colleges students need the guidance in the whole course from the entrepreneurship mentors due to the lack of practical experience in project selection, team building, project packaging, financing channels and other aspects, but these teams in many universities are uneven, andprofessional teachers with insufficient practical abilities are busy with teaching and scientific research, while the entrepreneurial mentors from enterprises are mostly part-time, and can not achieve refined guidance.

\subsubsection{Lack of Market Development and Operation Team}

The entrepreneurship projects where college students obtained success are more geared to the needs of student market, namely, the technical entrepreneurship or Internet entrepreneurship which can grasp the consumer psychology of peers. The achievement transformation of these projects requires to be operated by professional market operation team, which is what universities lack.

\subsubsection{Imperfect Organizational Structure}

Many colleges and universities have no specialized agencies with higher level to manage the maker space. The whole innovation and entrepreneurship work managed by different departments, need the coordination and communication among different departments such as the Youth League Committee, the dean's office, the scientific research department, the enrollment and employment department, various secondary colleges, etc., which are independent of each other, thus the resources related to college students' innovation and entrepreneurship can not be efficiently integrated.

\subsubsection{Overemphasis on Space Construction and Incubation Performance}

Many management layers of colleges and universities have misunderstood the construction of maker space with an overemphasis on space construction, the number of settled projects and incubation performance, ignoring the content construction and the effect of "learning by doing", thus resulting in the untight combination of innovation, entrepreneurship education and professional education, and the big difference between maker space culture and school culture.

\subsection{Survey on Students’ Demand for Innovation and Entrepreneurship}

In order to understand the current situation of students' innovation and entrepreneurship, dig up the entrepreneurial bottleneck and difficult problems with universality, and accurately define the needs of students in innovation and entrepreneurship, the "survey on the cultivation of innovative and entrepreneurial talents" was conducted in this paper through the "questionnaire star" platform, and a total of 212 valid questionnaires were recovered. The survey data show:

More than $60 \%$ are interested in entrepreneurship, and the more junior students are, the more 
they are willing to innovate and start their business;

The main reasons of choosing innovation and entrepreneurship are respectively as: Improvement of professional skills for the employment (71.7\%), enrichment of self experience and self challenge (66.5\%), and earning money (52.8\%);

The students who have settled in college students' platform of innovation and entrepreneurship have more obvious advantages in professional knowledge and practical skills;

The students with entrepreneurial experience account for 25\% with the Internet entrepreneurship as the main choice due to its advantages of large platform and low cost;

The biggest bottlenecks in innovation and entrepreneurship are respectively as: Difficult market promotion (79.7\%), insufficient capital (76.4\%) and supply of goods (64.6\%), while the professional skills are generally not considered as the biggest obstacle to entrepreneurship;

The most desired supports from schools are respectively as: Practical training opportunities (96.2\%), establishment of special fund to support innovative and entrepreneurial projects (73.1\%) and organization of professional competition (40.1\%).

In the investigation, the students also put forward some suggestions for the training of innovative and entrepreneurial talents: The first is to increase the proportion of training courses, so as to improve professional skills through practical training; the second is to expand the management and operation team of maker space, improve the quality of enterprises in the maker space, and introduce more TP projects to increase students' opportunities for actual combat; the third is to perfect the tutor system of innovation and entrepreneurship and organize more innovation and entrepreneurship competitions; the fourth is to organize the entrepreneurship education of interdisciplinary to help students to conduct entrepreneurial psychological construction.

\section{Effective Supply of Maker Space in Colleges and Universities}

\subsection{Construction of Operation System for Talent Training and Social Service}

\subsubsection{Guidling Ideology on Construction}

In the guiding ideology on the construction of maker space in colleges and universities, it should be clear that the ultimate goal is not to hatch how many enterprises, and more importantly, to mobilize and stimulate the innovative spirit and creativity of the majority of students, so as to promote the upgrading and updating of innovative and entrepreneurial education, which requires that the construction of maker space should return to the essence of education, not only for the needs of innovation and Entrepreneurship of students, but also to serve the development of regional economy, overall, the operation system of maker space should be constructed for talent training and social service.

\subsubsection{Overall Development Structure}

In the overall development framework, it should create the "integration of three layers into progressive type" service, while the lower layer is the support of the upper layer, and the upper layer is the progressive layer of the lower layer. The lower layer complied with the trend of open and public innovation in the 2.0 era, constructs work space, network space, social space and resource sharing space with the maximum radiation across the campus; the middle layer pays attention to content construction with the most urgent innovation and entrepreneurship needs for students, aiming at solving the problems of innovation and entrepreneurship; the upper layer with the market-oriented operation mode, introduces the participation of professional institutions to seamlessly integrate students' innovative and entrepreneurial achievements with social service. 


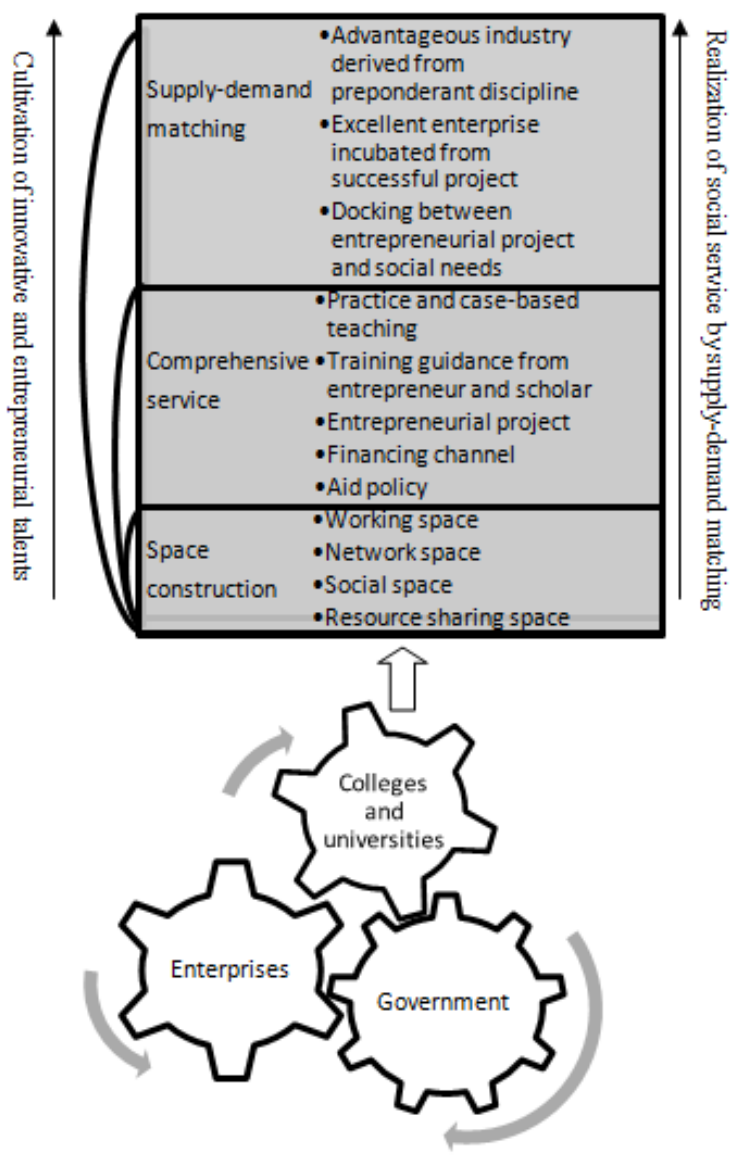

Figure 1 Operation System of Maker Space for Talent Cultivation and Social Service.

\subsubsection{Space Operation Mode}

In the mode of space operation, assemble the forces in schools, local government and enterprises to realize the "cooperation among schools, local government and enterprises, school running with park industrialization", effectively make use of policy integration effect to open up innovation and entrepreneurship park, attract enterprises to settle down through market mechanism to provide specialized services for the innovative and entrepreneurial activities in colleges and universities, and integrate the hardware and software resources in campus to help students to realize the supplydemand matching between innovation and entrepreneurship projects and markets.

\subsubsection{Key Contents in Construction}

In the whole system, the construction focuses on the content construction of the middle level. Colleges and universities should not only provide the entrepreneurial studio with perfect supporting facilities at the bottom to build a large data center and other specialized technical service platform, but it is more important to explore how to establish the effective incentive mechanism and safeguard measures, achieve the introduction of innovative and entrepreneurial projects with high quality, organize the "entrepreneur forum" with certain level and case teaching, and help students to overcome the bottlenecks of innovation and entrepreneurship effectively, so as to more smoothly promote the supply-demand matching between innovation and entrepreneurship projects with social needs. 


\subsection{Effective Supply Strategy of Maker Space in Colleges and Universities}

In order to give full play to the effective supply of maker space for the innovation and entrepreneurship education in colleges and universities, and excavate its maximum value, not only need the innovation resources to be opened with students as the center, but also the attention should be paid to the interest demands of the main participants, such as cooperative enterprises and teachers, while the reform of supply side should be adopted to stimulate the enthusiasm and creativity of all parties, and improve the quality of space construction.

\subsubsection{Policy Incentive and System Guarantee}

In order to encourage teachers and students to extensively participate in innovation and entrepreneurship, it is necessary for schools to introduce incentive policies for the cultivation of innovative and entrepreneurial talents. For teachers, guiding students to participate in innovative and entrepreneurial activities will be included in personal workload, the achievements of tutors in innovation and entrepreneurship activities will be included in the title evaluation system, and the reward system will be implemented for excellent tutors; for students, set up compulsory credits for innovation and entrepreneurship in talent training program, increase the proportion of practice course credits and hours, the achievements of students in innovation and entrepreneurship activities will be included in credits, credit mutual recognition will implement the exemption from some courses, the achievement of innovative practice will be included in students' comprehensive evaluation system, which should be given priority in scholarship grant, international student exchange program and other projects, and establish support fund for college students' innovation and entrepreneurship.

\subsubsection{Project Leading and Collaborative Innovation}

On the one hand, the school introduces enterprise resources, provides innovation and entrepreneurship projects, and drives the students to carry out entrepreneurship practice on campus, on the other hand, the school actively encourages students to lead innovation and Entrepreneurship with interest, and give full play to the leading role of students in project selection, team building, funding spending, achievements transformation and other aspects, so as to realize the students' independent decision-making and independent entrepreneurship. No matter what forms of innovation and entrepreneurship practice will be conducted, the maker space should give full play to its function of practice guidance base, while the entrepreneurial tutors from different professional fields will provide guidance and training to realize the interdisciplinary integrated entrepreneurship education, and carry out the all-the-way guidance in the form of "one-to-one" by adopting tutorial system, requiring the project teams to demonstrate and exchange their latest achievements in maker space at regular intervals.

\subsubsection{Promoting Learning and Teaching with Competition}

Support students to participate in all kinds of national and provincial innovation and entrepreneurship competition, and encourage students to compete with the excellent students in similar colleges on the same stage, while the guidance teachers should participate in the whole process including pre competition preparation, competition scene, and summary stage after the game. This form of "promoting learning and teaching with competition" can not only make students improve the breadth and depth of professional knowledge learning in a short time so as to grow rapidly in the ideological sparks of innovation and entrepreneurship, but also make teachers strengthen inter school exchange and industry dialogue when guiding the competition so as to fully 
improve the abilities of practical teaching and case-based teaching. Those who have achieved excellent results in the national and provincial academic competitions will be provided with the opportunity to settle in the entrepreneurship studio of maker space so as to promote achievement transformation.

\subsubsection{School-enterprise Cooperation and Resource Sharing}

Enterprises as the most active factor in economic organization should play a leading role in the realization of "school-government-enterprise" linkage to create the construction mode of maker space with win-win cooperation. The school-enterprise cooperation is beneficial for all participants: School's professional construction and talent training will have a definite object in view, and the enterprise can cultivate its own applied talents with high level in advance; students can enjoy better resources and lay the foundation for the job; the government can improve social profits by fully integrating educational resources. Therefore, in the construction of maker space, the school should open the campus resources such as laboratory, library and innovative practice base, attract excellent enterprises and mentors to settle in school with support of advantageous discipline, and strengthen cooperation and exchange with enterprises by being equipped with exclusive site and staffing.

\section{Conclusion}

In a word, when responding to the national call of speeding up the construction of maker space, the colleges and universities firstly need to make clear the function and demand of maker space construction, avoiding misunderstanding. From the perspective of supply-side reform, only fully excavate the function of innovation and entrepreneurship education of the maker space in colleges and universities, and make use of policy incentive, system guarantee and innovation measures with the mode of "school-government-enterprise" linkage" to stimulate the enthusiasm of enterprises, teachers and students to participate actively, thus only in this way can we give full play to the maximum value of the maker space and eliminate some obstacles in the current reform of innovation and entrepreneurship education.

\section{References}

[1] General Office of the State Council (2015). Guiding Opinions of the General Office of the State Council on the Development of Maker Space to Promote Public Innovation and Entrepreneurship [online]. Available at: Http://www.gov.cn/Zhengce/content/201503/11/content_9519.htm.

[2] Haomin Zhang, Lei Du \& Jun Ma (2011). The excavation and integration of entrepreneurship education function of University Incubator Park, Innovation and Entrepreneurship Education. 2(6), p7-11.

[3] Zhanren Wang, Haibin Liu \& Zhongyuan Li (2016). Research on the role of maker space in college innovation and Entrepreneurship Education, Ideological and Theoretical education. Vol.2, p85-91. 